\title{
Simultaneous brightness contrast as a function of repeated trials
}

\author{
GARY MCCLURE and KENDON SMITH, \\ University of North Carolina, Greensboro, \\ N.C. 27412
}

Each of five Ss, over a priod of 10 successive days, made 500 judgments in a simultaneous brightness contrast situation, being given no knowledge of results. Contrary to expectation, the illusion showed a tendency to increase with repeated exposure; furthermore, intercurrent control judgments also showed significant changes with time. The findings pose a problem for either a judgmental or a retinal theory of brightness contrast.

Berman \& Leibowitz (1965) and Parrish \& Smith (1967) have noted the contemporary tendency to explain simultaneous brightness contrast in terms of retinal function (cf. Hurvich \& Jameson, 1964; Ratliff, 1965; Hurvich \& Jameson, 1966). Somewhat contrary to that tendency, both Berman \& Leibowitz (1965) and Parrish \& Smith (1967) have presented results strongly suggesting the importance, in simultaneous brigh tness contrast, of more central, "judgmental" factors. The former Es showed that appropriate division of the visual field by fine lines enhanced contrast effects, even though it is unlikely that the lines used could have had any material effect at the local, retinal level. The latter Es found that attitudinal instructions to $S$ affected the degree of brightness contrast: Ss told to adopt an "analytical" set reported significantly less effect than Ss told to adopt a "whole-perceiving" attitude.

The Parrish \& Smith (1967) study was originally suggested by Benussi's (1904) investigation of the effect of perceptual attitude upon the magnitude of the Müller-Lyer illusion. Another area of work with the Müller-Lyer illusion has concerned itself with the effects of repeated exposure (e.g., Judd, 1902; Lewis, 1908; Köhler \& Fishback, 1950; Mountjoy, 1958; Day, 1962; Dewar, 1967). The usual result of such exposure has been a decrement in the illusion; and the usual interpretation of that result has been one in terms of perceptual learning and increased objectivity of judgment. The present experiment was suggested by this second sort of investigation. It measured the effects of repeated exposure to the simultaneous brightness contrast situation, expecting to find a decremental effect and thus to provide additional evidence against a purely retinal explanation of simultaneous brightness contrast.

\section{METHOD}

The Ss were five advanced students in psychology (four graduate students, one honors senior; three male, two female; mean age, 24 years).

The principal item of apparatus was a "Brightness Comparator," Model V-0659 (Itek Corporation, 10 Maguire Road Lexington, Massachusetts 02173). This instrument provides for the independent control of each of four electroluminescent plaques. The plaques are arranged in pairs, one member of each pair consisting of a disc $10.5 \mathrm{~cm}$ in diam, the other member consisting of an annulus, $20 \mathrm{~cm}$ o.d., immediately surrounding that disc. Each pair of plaques is mounted on a single metal panel, the control leads for that panel being carried as a single, light cable to the control unit. The latter provides four calibrated knobs, used in adjusting the luminance of the respective plaques over a range of 0 to $5 \mathrm{ft}-\mathrm{L}$ (achromatic).

The experimental apparatus was situated in a classroom of medium size. The room was air-conditioned. It could be darkened completely, as it was during all experimental sessions. The luminous panels were placed $22 \mathrm{~cm}$ apart and $107 \mathrm{~cm}$ above floor level, on centers. A table and chair for $S$ were placed directly in front of the panels, $S$ 's eyes being at a distance of $185 \mathrm{~cm}$ from the panels and on a level with them. To the right of $S$, on the table at which he sat, was placed the control unit for the plaques. $S$ could reach the unit comfortably with his right hand; the unit could also be operated by $\mathrm{E}$, who sat directly before it and thus also to the right of $S$.

Liberal use of black velvet coverings and partitions reduced reflections and other visual distractions to negligibility. A continuous strip of heavy rubber was placed around the single control knob used by $S$, any possible tactual cues from the surface of the knob being thereby eliminated.

Each $S$ participated in a 1-h individual session on each of 10 successive days. Each session began with a 12-min dark-adaptation period. The disc on S's left was then set at $1 \mathrm{ft}-\mathrm{L}$, the annulus surrounding it being left dark; and $S$ made five ascending and five descending adjustments of the knob controlling the disc on his right, in an effort to match the brightness of the left-hand (standard) disc. This control series completed, $\mathbf{S}$ then performed 25 ascending and 25 descending trials under the experimental condition: the standard disc remained at $1 \mathrm{ft}-\mathrm{L}$, the annulus surrounding it was set at $4 \mathrm{ft}-\mathrm{L}$, the variable disc was under S's control, and the annulus surrounding the variable disc remained dark. The order of ascending and descending trials was determined throughout by table of random numbers; on any trial, nevertheless, $S$ was free to reverse the direction of adjustment as often as he wished in reaching a satisfactory setting. The standard disc was always on S's left, the variable disc always on his right.

Each S, as may be seen, performed a total of 100 control trials and 500 experimental trials, in 10 successive days. All Ss understood completely the nature and purpose of the study; in fact, they were asked to adopt as critical and objective an attitude as possible toward their task. At no time during their service, however, were they allowed to know what settings they were actually making.

\section{RESULTS AND DISCUSSION}

The results of the experiment are shown by Fig. 1 . There, the mean judgments per day in the control condition and in the experimental condition, respectively, are shown graphically. It will be noted that the ordinate in Fig. 1 is scaled logarithmically, such scaling seeming to reflect the underlying psychophysics of the situation most accurately.

Although it had been anticipated that the trend of the curve for the experimental condition would be upward, the actual tendency of the curve is rather regularly downward. Analysis of variance across days ( $d f=9 / 36$ ) shows $p=.054$, a value which should probably be taken seriously, in view of the contrary nature of the findings.

Even the control condition yielded an unexpected result. As will be noted in Fig. 1, the curve for that condition does stay fairly close to unity, as was anticipated. The curve tends to dip slightly throughout its middle range, however, and an analysis of variance

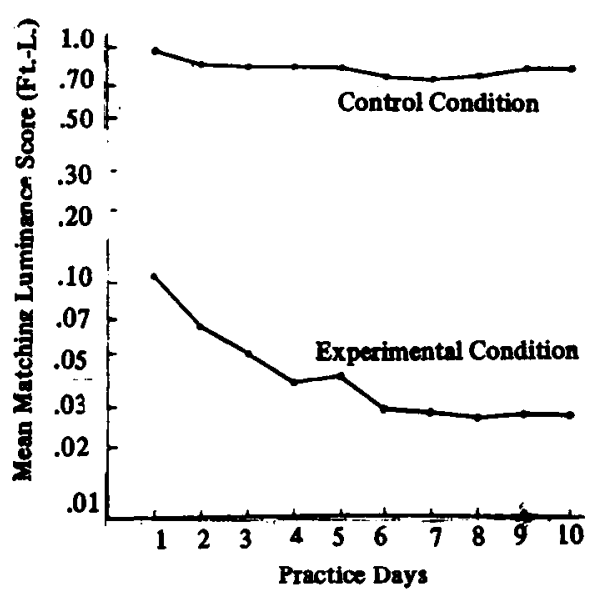

Fig. 1. Mean judgments per day, control condition, and experimental condition. Note logarithmic ordinate. 
across days ( $d f=9 / 36)$ shows a clearly significant effect $(p<.01)$.

It is of incidental interest that, in both the experimental condition and the control condition, the between-Ss effect was significant ( $d f=4 / 36, p<.01$, in each case).

The results of the present study obviously challenge explanation by any current theory. Our own speculation would be to the effect that the Ss were able to maintain an anlytical attitude and to be somewhat objective, in the experimental condition, during the early stages of their service, but that, as time passed and motivation perhaps weakened, the $S s$ became less critical and their perceptions less realistic. We might then imagine that their tendency to perceive the standard disc as darker and darker during the experimental phase transferred itself in some degree even to the judgments made in the control condition. Clearly, though, such an argument is a weak, ad hoc thing, and there is no obvious explanation in judgmental terms for the results reported here. It should be pointed out, however, that the data would be at least as difficult to explain at the purely retinal level. What scems to be required is additional, clarifying investigation.

\section{REFERENCES}

BENUSSI, V. Zur Psychologie des Gestalterfassens. In A. Meinong (Ed.), Untersuchungen zur Gegenstandstheorie und Psychologie. Leipzig: Barth, 1904.

BERMAN, P. W., \& LEIBOWITZ, H. W. Some effects of contour on simultaneous brightness contrast. Journal of Experimental Psychology, $1965,69,251-256$

DAY, R. H. The effects of repeated trials and prolonged fixation on error in the Müller-Lye figure. Psychological Monographs, 1962, 76, No. 533 .

DEWAR, R. Stimulus determinants of the practice decrement of the Müller-Lyer illusion. Canadian Joumal of Psychology, 1967, 21, 504-520.

HUR VICH, L. M., \& JAMESON, D. Outlines of a theory of the light sense. Cambridge, Mass.: Harvard University Press, 1964. (Translation of: Hering, E. Grundzüge der Lehre vom Lichtsinn. Berlin: Springer, 1920.)

HURVICH, L. M., \& JAMESON, D. The perception of brightmess and darkness Boston: Allyn \& Bacon, 1966.

JUDD, C. H. Practice and its effects on the perception of illusions. Psychological Review, 1902,9, 27-39.

KÖHLER, W., \& FISHBACK, J. The destruction of the Müller-Lyer illusion in repeated trials: 1 and II. Journal of Experimental Psychology, $1950,40,267-281$ and $398-410$.

LEWIS, E. O. The effect of practice on the perception of the Müller-Lyer illusion. British Journal of Psychology, 1908, 2, 294-306.

MOUNTJOY, P. T. Effects of exposure time and intertrial interval upon decrement to the Müller-Lyer illusion. Joumal of Experimental Psychology, 1958, 56,97-102.

PARRISH, M., \& SMITH, K. Simultaneous brightness contrast as a function of perceptual set. Psychonomic Science, 1967, 7, 155-156.

RATLFF, F.Mach bands: Quantitative studles on neural networks in the retina. San Francisco: Holden-Day, 1965.
NOTE

1. This paper is based upon research done for the Master's thesis by the first author, who is now at the Department of Psychology of the University of Vermont, under the direction of the second author. The latter prepared the present report.

\section{Generalization of a voluntary response as a function of presentation frequency of the training stimulus in testing?}

JOHN A. HEBERT, ${ }^{2}$ Colorado State University, Ft. Collins, Colo. 80521, and JACK E. CAPEHART, University of Arizona, Tucson, Ariz. 85721

Frequency of presentation of the original training stimulus in the test phase of a study of human voluntary generalization was found to affect the form of the generalization gradient on a weight dimension. That is, in a situation in which all of the additional test stimuli are larger than the original training stimulus, and all stimuli are presented with equal frequency, a tendency to choose stimuli toward the middle of the test range as the original was observed. However, if the original stimulus was presented more frequently than any of the other stimuli in testing, Ss tended to choose the original "correctly," yielding a "typical" unidirectional generalization gradient.

In a voluntary response generalization test, it is not unusual to present the original training stimulus (S1) more frequently in the test phase than the additional test stimuli. This procedure of "overrepresenting" $\mathbf{S 1}$ in testing, or the procedure of "booster" trials with S1 interspersed with test trials, may actually produce generalization gradients quite different from those obtained with a procedure in which $S 1$ is presented with the same frequency as each of the test stimuli, i.e., S1 is treated as just another test stimulus. Examination of the literature points to such a possibility. A study by White (1965) illustrates the overrepresentation procedure. White trained human Ss to respond to a red-colored stimulus by pushing a lever upward. Ss were also instructed to push the lever downward if they saw any stimulus other than the red one (S1). A test series consisted of 16 presentations of S1 interspersed with three presentations each of the additional test stimuli (S2 through S5). All of the additional test stimuli were in the direction of shorter wavelengths from S1 (i.e., unidirectional testing). White found that response was greatest to $S 1$ and that it decreased as similarity to $S 1$ decreased, i.e., a "typical" unidirectional gradient. However, a study by Thomas \& Jones (1962), illustrating the equal presentation procedure, produced somewhat different results. Ss were exposed to a 525-mu stimulus for a brief time and were told to release a key only if they saw that value again in a test series. In the groups receiving unidirectional testing, that is, test stimuli being either all shorter or all longer than $S 1$ in wavelength, Thomas and Jones reported that Ss tended to choose stimuli in the center of the test range (e.g., S2 or S3) more than the decentered S1. Instead of a gradient with a peak at $S 1$ with a steady decrement to S5, as in the White study, Thomas and Jones reported a peak at $S 2$ with a decrement in either direction. While these two studies are really not very comparable because of many minor differences, it is possible that the differences in presentation frequency of S1 in test is the reason for the difference in the gradient form. A replication of the Thomas and Jones' finding of a "central-tendency" by Helson \& Avant (1967), with a size dimension and an equal presentation procedure, makes this hypothesis more compelling.

This present study investigates the effect of "overrepresentation" of S1 in testing. A wavelength dimension was not chosen because of the possibility of $S$ using verbal labels in the task of identifying stimuli. The label "red," for example, is an appropriate label for wavelengths of specific value and, conceivably, could help $\mathrm{S}$ to tie down the stimuli. Work by Thomas and his coinvestigators (Thomas \& Mitchell, 1962; Thomas \& Bistey, 1964; Thomas \& 